\title{
Os efeitos de sentido do som no cinema documental e o contrato de veridicção
}

\author{
Alexandre Provin Sbabo*
}

Resumo: Por diversas vezes, o cinema documental foi visto como um cinema que, para ter credibilidade e veracidade, enfatizava o conteúdo em detrimento da expressão, focando o fato histórico e sua narrativa. O presente artigo procura explorar a problemática do uso do som diegético e não diegético no cinema documental, a partir dos pressupostos da teoria do audiovisual em diálogo com a teoria semiótica francesa de Greimas.

Palavras-chave: documentário; diegético; semiótica; som; contrato de veridicção.

Resumen: En varias ocasiones el cine documental se ha visto como un cine que, para tener credibilidad y veracidad, enfatizaba el contenido en detrimento de la expresión, enfocando el hecho histórico y su narrativa. El presente artículo busca explorar la problemática del uso del sonido diegético y no diegético en el cine documental, a partir de los presupuestos de la teoría del audiovisual en diálogo con la teoría semiótica francesa de Greimas.

Palabras clave: documental; diegético; semiótica; sonido; contrato de veridicción.

\begin{abstract}
On several occasions, documentary cinema was seen as a cinema that, in order to have credibility and truthfulness, emphasized content to the detriment of expression, focusing on historical fact and its narrative. This article seeks to explore the problem of the use of diegetic and non-diegetic sound in documentary cinema, based on the assumptions of the audiovisual theory in dialogue with Greimas' french semiotic theory.
\end{abstract}

Keywords: documentary; diegetic; semiotics; sound; veridiction contract.

Résumé : À de nombreuses reprises, le film documentaire a été considéré comme un cinéma qui, pour être à la fois crédible et véridique, souligne le contenu au détriment de l'expression, en se concentrant sur des faits historiques et leur mode narratif. Le présent article vise à examiner la question de l'utilisation du son diégétique et non diégétique dans le cinéma documentaire à partir des hypothèses de la théorie audiovisuelle en dialogue avec la théorie sémiotique française de Greimas.

Mots-clés : documentaire ; diégétique ; sémiotique ; son ; contrat de véridiction.

* Doutorando. Pontifícia Universidade Católica de São Paulo - PUC-SP, Programa de Pós-Graduação em Comunicação e Semiótica, Centro de Pesquisas Sociossemióticas. Bolsista CNPq. 05014-901, São Paulo, Brasil. E-mail: alexandre_sbabo@ho tmail.com

Submissão do artigo: 31 de maio de 2017. Notificação de aceitação: 13 de julho de 2017.

Doc On-line, n. 22, setembro de 2017, www.doc.ubi.pt, pp. 85-94. 


\section{Introdução}

Imagem e som sempre foram objetos de fascínio e de estudo, estando estes separados, como no caso das pinturas, fotografias, músicas, canções, etc., ou em relação, desde os diaporamas mais antigos até as mais recentes produções audiovisuais para o cinema, televisão ou internet. O que nos chama atenção é que, se enquanto linguagens individualizadas já são capazes de nos contagiar estesicamente, o que dizer, então, dos efeitos de sentido manifestados quando estas linguagens são postas em sincronia?

Desde o surgimento do cinema falado, em 1927, até os dias atuais, a sincronização de sons e imagens é capaz de causar uma série de efeitos de sentido em seus espectadores, levando-os aos mais diversos estados passionais, como, por exemplo, a tristeza, a alegria eufórica, a angústia, o medo, além de potencializar a carga dramática das imagens em movimento.

Cabe aqui salientar que, ao mencionarmos o surgimento do cinema falado datado de 1927, estamos nos referindo ao cinema que sincroniza o áudio e o vídeo, pois anterior à esta data, como afirma Garcia (2014: 137), algumas exibições cinematográficas já eram acompanhadas por instrumentos musicais, o que proporcionava certo sincretismo das linguagens, mas não a sua sincronização em um mesmo objeto tecnológico como no caso de The Jazz singer (1927).

Em se tratando das pesquisas, muitos aspectos têm sido estudados no que diz respeito aos efeitos de sentido do sincretismo entre música/canção e imagem em movimento, em especial no cinema ficcional, como foi o caso de Chion (1994, 1995) e Eisenstein (2002a, 2002b), isto sem mencionar os diversos estudos sobre a relação entre música e imagem em anúncios publicitários.

Entretanto, o sincretismo destas linguagens é muito pouco explorado no cinema documental e menos ainda quando falamos do cinema documental brasileiro. Em dada medida, tal afirmação se faz verdadeira em decorrência dos pequenos investimentos realizados neste gênero cinematográfico. De acordo com o website Portal Brasil (2013), ${ }^{1}$ houve um aporte de capital para investimento em 41 produções audiovisuais de longa-metragem no valor de $\mathrm{R} \$ 50$ milhões, porém somente 3 documentários faziam parte deste projeto, um índice menor que $8 \%$.

Ainda sobre a problemática do investimento no cinema documental, em setembro de 2016, a Agência Nacional do Cinema (ANCINE) ${ }^{2}$ divulgou em

1. Portal Brasil (2013). $\mathrm{R} \$ 50$ milhões são investidos na produção de 41 projetos de longametragem. Disponível em: www.brasil.gov.br/cultura/2013/02/r-50-milhoes-sao-investidos-naproducao-de-41-projetos-de-longa-metragem

2. Agência Nacional do Cinema (2016). Programa Brasil de Todas as Telas divulga investimentos em novos projetos para o cinema e a TV. Disponível em: www.ancine.gov.br/pt- 
seu portal a notícia de que 16 projetos foram contemplados pelo programa de incentivo Brasil de Todas as Telas, dentre os quais, somente 2 representavam o cinema documental de longa-metragem.

Portanto, o baixo investimento em conjunto com a pouca visibilidade das produções do cinema documental brasileiro contribui e justifica, em certa medida, a quase inexistência de estudos direcionados a este tipo de produção cinematográfica e, em quantidade ainda menor, pesquisas voltadas para a construção do sentido e dos efeitos de sentido manifestados em decorrência do sincretismo das linguagens sonora e visual.

Com estas observações, estamos colocando o cinema ficcional de um lado e o cinema documental de outro, uma vez que o primeiro recebe maior aporte de capital para investimento que o segundo e, além disso, a quantidade de estudos que tratam como objeto o cinema ficcional é significativamente maior que as produções acadêmicas voltadas para o cinema documental.

Entretanto, apesar das diferenças quantitativas, expostas anteriormente, nos questionamos se qualitativamente, no fazer estético do cinema, especificamente na relação entre as linguagens sonora e visual, há a reiteração destas divergências. Desta forma, observaremos o uso da linguagem sonora no cinema documental com base na literatura que compreende o sincretismo e os efeitos de sentido desta linguagem em relação sincrética com a imagem, com vistas a discorrer sobre possíveis diferenças e similitudes entre fazer estético do cinema ficcional e documental.

\section{O documentário}

Antes de adentrarmos nos tópicos sobre os efeitos de sentido do fazer estético relativos ao sincretismo da linguagem sonora e imagética, acreditamos ser de suma importância tentarmos trazer clareza para o que estamos denominando de cinema ficcional e cinema documental.

Para tal, ressaltamos o caráter polêmico das respectivas definições e distinções conceituais bem pontuadas por Braga e Costa (2014), Nichols (2010) e Bernardet (1990), que discorrem sobre a unicidade da linguagem cinematográfica abarcando tanto o cinema documental, como o ficcional. Para os autores, de maneira geral, a linguagem cinematográfica se propõe a contar uma história, sendo ela real ou não e é a partir deste ponto que começam as divergências conceituais.

Rotha (1939) explica que a principal diferença entre o cinema documental e o cinema ficcional está no caráter autêntico do primeiro em oposição ao

br/sala-imprensa/noticias/programa-brasil-de-todas-telas-divulga-investimentos-em-novos-pro jetos-para-o 
caráter teatral do segundo. Já Nichols (op. Cit.) comenta que esta relação indexadora de autenticidade existe tanto no cinema ficcional quanto no cinema documental, porém o que realmente diferencia um caso de outro é a relação entre personagens reais e personagens imaginários.

Na ficção, desviamos nossa atenção da documentação de atores reais para a fabricação de personagens imaginários. Afastamos temporariamente a incredulidade em relação ao mundo fictício que se abre diante de nós. No documentário, continuamos atentos a documentação do que surge diante da câmera. (ibid.:65 -66).

O autor continua sua diferenciação entre o cinema documental e ficcional afirmando que "o documentário re-apresenta o mundo histórico, fazendo um registro indexado dele; ele representa o mundo histórico, moldando seu registro de uma perspectiva ou de um ponto de vista distinto" (ibid.: 67).

Nichols (ibid.), assim como Braga e Costa (op. Cit.), acredita no poder que a linguagem cinematográfica tem de subverter o juízo lógico do espectador por meio da suspensão temporária da nossa incredulidade, especialmente no cinema ficcional, estabelecendo, assim, o que Greimas (1978: 214) denomina de contrato de veridicção.

[...] o discurso pode ser considerado como o espaço, o lugar frágil em que se inscreve e em que se lêem a verdade e a falsidade, a mentira e o segredo, que esses modos da veridicção resultam da dupla contribuição do enunciador e do enunciatário, que suas diferentes posições fixam-se apenas sob a forma de um equilíbrio mais ou menos estável que provém de um acordo implícito entre os dois actantes da estrutura da comunicação. Designa-se esse entendimento tácito por contrato de veridicção.

Podemos pensar, portanto que, se de um lado Nichols (op. cit.) e Braga e Costa (op. cit.) concordam que há uma suspensão da incredulidade na teatralização do cinema ficcional com a inserção de personagens imaginários, do outro lado isso só se torna possível por meio de um contrato de veridicção estabelecido entre enunciador e enunciatário.

Sendo assim, a proposta de Greimas (op. cit.) dialoga com os postulados de Nichols (op. cit.), Braga e Costa (op. cit.), uma vez que a suspensão da incredulidade ocorre por intermédio de um contrato de veridicção estabelecido entre enunciador e enunciatário, produzindo um efeito de sentido típico do cinema ficcional, assim como a manutenção da credulidade por parte do enunciatário e da fidúcia factual do enunciador possui como pano de fundo um contrato de veridicção envolto de um efeito de sentido mais próximo do cinema documental.

Tal ponto de vista torna-se mais complexo se aproveitarmos as contribuições de Bernardet (op. cit.) e Nichols (op. cit.) quando discorrem que, por 
mais fiel e indexadora que a imagem possa ser ao fato, não podemos nos esquecer que por trás deste discurso há escolhas do enunciador que potencializam ou minimizam certos efeitos de sentido. A escolha por uma tomada em close-up possui um efeito de sentido totalmente diferente de um plano americano ou de um plano geral.

Estas escolhas enunciativas em si não modificam a relação com o fato apresentado, mas constroem um efeito de sentido proposto pelo enunciador, o que por si só já poderia, em certa medida, dissimular a relação de verossimilhança com a realidade representada. Partindo disto, nos parece, então, inviável a definição do documentário como um representante da realidade ou da verdade, transformando-o, contudo, em uma representação de uma determinada verdade ou de uma realidade específica, potencializada, obviamente, pela relação indexadora da imagem e pela construção da narrativa por meio de personagens efetivamente reais. Portanto, ampliaríamos o conceito de documentário proposto por Nichols (ibid.: 68) de um "tratamento criativo da realidade" para um tratamento criativo de uma realidade ou verdade específica, pois assim abarcamos com maior sucesso a especificidade de cada enunciado, admitindo diferentes perspectivas sobre um mesmo tema.

Com isso, além de descartarmos uma possível ingenuidade do enunciador e acrescentarmos a questão do ponto de vista, admitimos, também, que o enunciador utiliza certas construções de sentido no cinema documental que possibilitam a firmação de um contrato de veridicção com seu enunciatário, como, por exemplo, personagens reais, sem abrir mão dos recursos estéticos da linguagem cinematográfica.

\section{O som no documentário}

Após compreendermos as articulações definidoras apresentadas acima, podemos enfim entrarmos no que concerne ao som e seus efeitos de sentido em sincretismo com a imagem na linguagem cinematográfica. Neste aspecto, devemos ressaltar que os estudos de Chion $(1994,1995)$ são balizadores para compreendermos a importância destes elementos no cinema.

Chion (1994: 5) propõe uma série de funções da música quando posta em relação com a imagem. Entre estas funções, o autor destaca o valor agregado ou adicionado que a música empresta à imagem, somando à esta última não somente expressividade, dramaticidade, densidade e profundidade, mas também informatividade.

Além disso, o autor (ibid.: 12) realça as características de temporalização da música no cinema, elencando três categorias, sendo elas: a animação tem- 
poral, a linearidade dos planos narrativos e a potencialização da dramatização de uma determinada cena ou plano.

No que tange o som no cinema, também não podemos deixar de fora três grandes classificações sonoras, o som diegético, o som não diegético e o som metadiegético, sendo estas categorias bastante amplas e as bases da discussão sobre o som no cinema ficcional e documental.

Gorban (1976) explica que o som diegético possui uma sonoridade objetiva, é todo som que também é perceptível aos personagens, como, por exemplo, a paisagem sonora de um bar no qual está ocorrendo determinada cena, o barulho de passos no corredor que o personagem escuta, etc. Os sons não diegéticos são sonoridades subjetivas, que os personagens não escutam e que são geralmente reconhecidos como trilhas sonoras, efeitos sonoros especiais, música de fundo que o personagem não escuta, etc. Já os metadiegéticos também são sonoridades subjetivas, mas dizem respeito ao imaginário particular de determinado personagem, sendo este, por vezes, associado ao não diegético. Munidos, portanto, de tais conceitos, podemos agora explorar as críticas ao uso, ou não uso, do som no cinema documental.

Lack (1997: 257), por exemplo, afirma que a "música tem a capacidade de mudar nossos sentimentos em relação ao objeto ao qual acompanha", podendo, em geral, deturpar a visão pré-concebida de realidade do e no documentário, passível de questionarmos até mesmo a autenticidade de tal obra documental. Donelly (2015: 140) explica que a partir da pressuposição de que o recurso sonoro não deveria sobrepor a representação da realidade:

[...] muitos realizadores evitaram a música dramática incidental como acompanhamento das imagens e dos sons diegéticos. Esses elementos sozinhos parecem transmitir a realidade diretamente enquanto a música não diegética, particularmente no seu estilo hollywoodiano, parece ser a personificação da manipulação emocional e a 'adição' estetizante da realização documentária.

Desta maneira, o som no documentário sempre foi muito questionado, não pela sua existência em si, mas pela sua qualidade dramática e pela estetização de uma representação da realidade. A inclusão de qualquer som não diegético poderia comprometer a percepção de autenticidade documental, assim como recobrir uma realidade com algo que não é própria dela, como, por exemplo, uma trilha sonora.

Criou-se, então, uma regra implícita de que um documentário, para ser considerado fiel ao fato e representar a realidade como tal, não teria a licença poética de usufruir das qualidades narrativas e dramáticas que uma trilha sonora poderia construir como efeito de sentido estético. Em outras palavras, a estética do documentário (para ser considerado hipoteticamente verídico) de- 
veria se resignar e se submeter somente as possibilidades diegéticas do som, mantendo assim o foco na representação do fato.

\section{A construção do efeito de sentido e o contrato de veridicção}

Após explorarmos as distinções conceituais entre o cinema documental e o cinema ficcional e as diferentes funções e classificações do som de maneira breve, passaremos a discutir sobre a possibilidade de utilizar sons tidos como não diegéticos no documentário, por meio da proposta do contrato de veridicção e dos ganhos ou perdas sobre os efeitos de sentido manifestados em tais obras.

Já vimos que a principal diferença entre o cinema documental e ficcional consiste nas diferentes formas que o enunciador constrói o fazer-crer. No primeiro, há a necessidade de um fazer-crer verdadeiro, enquanto que no segundo o fazer-crer está direcionado para a suspensão da realidade. Em outras palavras, um se esforça para construir um efeito de sentido de verdade por meio do fato real e o outro se esforça para construir um efeito de realidade dentro de um mundo ficcional. Observando a partir da sintaxe narrativa, nos parece bastante simples tal diferenciação, contudo, a manifestação ou expressão destas torna-se o problema central deste estudo.

No nível discursivo, tanto o cinema documental como o ficcional possuem os mesmos recursos de linguagem, ou seja, estão sujeitos às mesmas variantes e invariantes, às mesmas condições de manifestação de sentido dentro das possibilidades da linguagem cinematográfica.

A busca pela diferenciação estética de um e de outro é o que constrói nosso objeto. O cinema ficcional, sem qualquer obrigatoriedade ou responsabilidade com o real e/ou verdadeiro, encontra-se permanentemente livre para explorar todo o repertório tecnológico e dramático, enquanto que o cinema documental, com a obrigatoriedade em construir sua narrativa com base na realidade e no verdadeiro, procura manifestar sua expressão no limiar do que é aceitável socialmente e eticamente como verdade.

Além disso, destacamos que a grande maioria das funções do som no cinema expostas por Chion anteriormente possui como efeito de sentido um aumento na dramatização, na profundidade e na densidade de determinada cena e, em um nível mais superficial, busca potencializar a imersão afetiva e passional do enunciatário na obra cinematográfica, com vistas à conjunção entre o enunciatário, sujeito espectador, e o objeto, a obra cinematográfica.

Do ponto de vista do cinema documental, quando o conteúdo é reconhecido como verdadeiro por meio de sua manifestação estética, há uma conjunção entre a mensagem do enunciador e o enunciatário. Caso não ocorra tal 
efeito de sentido de verdade, então o enunciatário passará a desacreditar das informações presentes no documentário e da sua veracidade de fato.

Com base nisso, podemos construir um quadrado semiótico, que consiste em uma "representação visual da articulação lógica de uma categoria semântica qualquer" (Greimas \& Courtés, 2013: 400) de maneira que possamos observar claramente a articulação entre as oposições semânticas de verdade vs ficção. Vale ressaltar que a poderíamos usar, obviamente, como oposição semântica o termo mentira, contudo a noção de ficção nos parece muito mais fértil no que diz respeito ao objeto analisado.

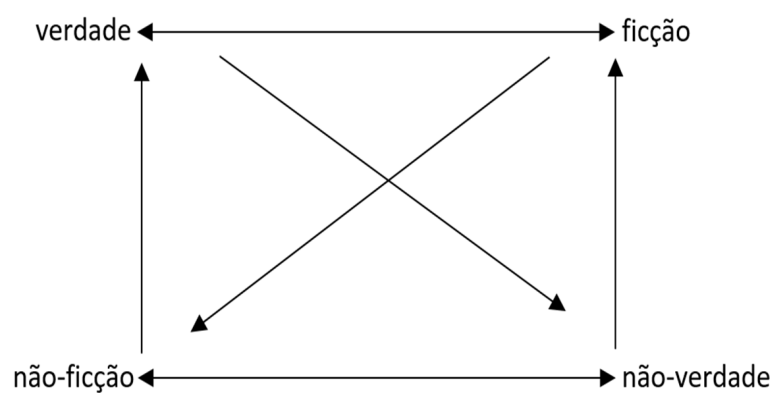

Sendo assim, o cinema documental acaba por se utilizar de recursos da expressão para homologar o caráter verídico de seu conteúdo. Isto explica, em certa medida, o motivo da preocupação no uso de sons não diegéticos nas obras do gênero, porém tal explicação não engloba a noção de ponto de vista do enunciador sobre o fato.

Retomando o conceito de documentário proposto anteriormente, como um tratamento criativo de uma verdade específica, abrimos caminho para o ponto de vista do enunciador sobre determinado fato e ao mesmo tempo tornamos clara a possibilidade da utilização da estética típica da linguagem cinematográfica para iluminar algum acontecimento histórico. O fato histórico da eleição do presidente dos Estados Unidos da América, por exemplo, poderia muito bem ser narrado sobre dois pontos de vista diferentes, ou republicano ou democrata, o que de maneira alguma deslegitimaria a veracidade do fato.

O cinema documental propõe uma discussão a partir de um acontecimento histórico, ou seja, o enunciador pode manifestar determinado conteúdo a partir de diferentes expressões sem perder o caráter verídico do fato e é neste ponto que o som diegético pode trazer ganhos expressivos para a estética documental. Fazer um documentário sobre a conquista de um campeonato mundial de futebol utilizando o $4^{\circ}$ movimento da $9^{\circ}$ sinfonia de Beethoven ou o $1^{\circ}$ mo- 
vimento da sonata para piano número 14 do mesmo compositor altera significativamente o humor do documentário e sua carga dramática, manifestando claramente o ponto de vista do enunciador sobre o objeto retratado, o que não significa que o fato em si seja alterado. Hjelmslev (1975: 57) explica esse mesmo processo por meio da teoria linguística no qual consiste em "enfatizar valores diferentes. numa ordem diferente, coloca o centro de gravidade diferentemente e dá aos centros de gravidade um destaque diferente". Por isso, a inserção do som não diegético no documentário altera os valores da obra, mas não o fato histórico retratado.

Desta forma, o fazer-crer na verdade do documentário não possui relação com a expressão sonora do filme, mas sim com o fato narrado. A justificativa do uso do som diegético, como ponto de partida para o estabelecimento de uma verdade e de um fazer-crer, torna-se praticamente insignificante perto da presença do fato histórico narrado. Não estamos dizendo que a música ou o som no documentário não seja importante, muito pelo contrário, porém, alertamos que a exaltação do uso do som diegético como justificativa de veracidade, não corresponde em sua totalidade às condições da veracidade para o estabelecimento de um contrato de veridicção, abrindo assim a possibilidade não só do uso do som diegético, mas também do som não diegético com vistas à manifestação de um efeito de sentido que entre em conjunção com a proposta do enunciador e não caminhe para uma esterilidade estética do som no documentário.

Consequentemente, as possibilidades do plano da expressão estarão à disposição do enunciador para, além de expor o fato histórico com caráter documental, permitir a exposição do ponto de vista ou da intenção do enunciador de maneira poética, adicionando ou subtraindo afetos e paixões da narrativa de um determinado conteúdo, sem que com isso invalide a obra como documentário em si. Assim, um documentário que procure expor as problemáticas da crise migratória de refugiados para a União Europeia poderá potencializar o efeito de sentido dramático sem que, com isso, perca sua primazia documental.

\section{Referências bibliográficas}

Bernardet, J. (1991). O que é cinema. São Paulo: Brasiliense.

Braga, M. H. \& Costa, V. (2014). Ficção \& documentário: hibridismo no cinema brasileiro contemporâneo. O percevejo online, 5 (2): 165-190. Disponível em: www.seer.unirio.br/index.php/opercevejoonline/article/view $13777 / 3270$

Chion, M. (1994). Audio-vision: sound on screen. Columbia University Press. 
Chion, M. (1995). La musique au cinéma. Paris: Librairie Arthème Fayard.

Donnelly, K. (2015). Irish sea power: a new version of man of Aran. In H. Rogers (ed.), Music and sound in documentary film (pp.137-150). New York: Routledge.

Eisenstein, S. M. (2002a). A forma do filme. Rio de Janeiro: Jorge Zahar.

Eisenstein, S. M. (2002b). O sentido do filme. Rio de Janeiro: Jorge Zahar.

Garcia, D. (2014). O som no cinema e a música concreta. FAP Revista Científica-UNESPAR, 10: 135-145. Curitiba.

Gorban, C. (1976). Teaching the soundtrack. Quarterly Review of Film Studies, November, 1: 446-452.

Greimas, A. J. (1978). O contrato de veridicção. Revista internacional de semiótica e linguística, 2 (1): 211-221.

Greimas, A. J. \& Courtés, J. (2013). Dicionário de semiótica. São Paulo: Contexto.

Hjelmslev, L. (1975). Prolegômenos a uma teoria da linguagem. 2. ed. São Paulo: Perspectiva.

Lack, R.( 1997). Twenty four frames under: a buried history of film music. London: Quartet Books.

Nichols, B. (2010). Introdução do documentário. Campinas-São Paulo: Papirus.

Rotha, P. (1939). Documentary film. New York: W. W. Norton \& Company.

\section{Filmografia}

The Jazz singer (1927), de Alan Crosland. 